\title{
La transformación del concepto de persona a la luz de la doctrina de la soberanía de Carl Schmitt
}

\section{The transformation of the concept of person in the light of Carl Schmitt's doctrine of Sovereignty}

\author{
Rafael Augusto Campos García-Calderón \\ Investigador independiente \\ Asociación de Teología Política Carl Schmitt de Lima, Perú \\ rafaelcamposgarciacalderon@hotmail.com
}

Resumen: La finalidad del presente artículo es descubrir la presencia del concepto de persona en la doctrina de la soberanía de Carl Schmitt. A pesar de que este concepto tuvo un amplio desarrollo metafísico en el seno del pensamiento cristiano durante la antigüedad tardía, jamás pudo desembarazarse de la impronta jurídica de sus creadores los juristas romanos. Por tal razón, sirvió como soporte conceptual para el posterior despliegue de la noción de persona jurídica, sistematizada a lo largo de la modernidad. Para lograr nuestro objetivo, intentaremos rastrear la transformación del concepto de persona a lo largo de la edad media y la modernidad, así como revisar el concepto de soberanía en la teoría política moderna. Por otro lado, estudiaremos la noción de decisión en la obra de Carl Schmitt, noción que el gran jurista alemán utilizó para definir su propia concepción de la soberanía. A partir de estas precisiones, intentaremos establecer la relación existente entre la noción de persona y la de decisión en el seno de la concepción schmittiana de la soberanía toman- 
do como hilo conductor los presupuestos teológicos implícitos en ella. Como veremos, tales presupuestos nos remitirán a la obra del pensador danés Søren Kierkegaard, cuyas doctrinas nos mostrarán todo el alcance del planteamiento schmittiano. De esta manera, podemos concluir que el concepto de persona subyacente al decisionismo schmittiano ha sido transformado, en primer término, en el de existencia política, noción determinada por la relación de enemistad; y, en segundo lugar, en el de unidad de la personalidad, concepto determinado por la actualización de la dimensión espiritual al interior de la condición humana.

Palabras clave: soberanía, decisión, persona, existencia, espíritu.

Abstract: The purpose of this article is to discover the presence of the concept of person in the Carl Schmitt's doctrine of sovereignty. Although this concept had a broad metaphysical development within Christian thought during late antiquity, it could never get rid of the legal imprint of its creators the Roman jurists. For this reason, it served as a conceptual support for the subsequent deployment of the notion of legal entity, systematized throughout modernity. To achieve our goal, we will try to trace the transformation of the concept of person throughout the middle ages and modernity, as well as review the concept of sovereignty in modern political theory. On the other hand, we will study the notion of decision in the work of Carl Schmitt, a notion that the great German jurist used to define his own conception of sovereignty. Based on these clarifications, we will try to establish the relationship between the notion of person and that of decision within the Schmittian conception of sovereignty, taking the theological presuppositions implicit in it as a guiding thread. As we shall see, such budgets will refer us to the work of the Danish thinker Søren Kierkegaard, whose doctrines will show us the full scope of the Schmittian approach. In this way, we can conclude that the concept of the person underlying Schmittian decisionism has been transformed, first, into that of political existence, a notion determined 
by the enmity relationship; and, secondly, in the unity of personality, a concept determined by the updating of the spiritual dimension within the human condition.

Keywords: Sovereignty, Decision, Person, Existence, Spirit.

Recibido: 30 de agosto de 2019

Aceptado: 15 de febrero de 2020 https://dx.doi.org/10.15174/rv.vi26.500

\section{De la persona al sujeto de derecho}

Ta noción de persona que la Edad Media conoció tuvo su oriLen en la concepción jurídica romana. Como se sabe, entre los romanos, se utilizó la palabra persona para designar el concepto jurídico respectivo, porque su significado originario permitía esta extrapolación conceptual. En efecto, la palabra persona proviene del verbo personare, utilizado para describir la máscara con la que los actores de teatro representaban a determinados personajes. Personare significaba literalmente "para sonar", puesto que se trataba de obtener un sonido más profundo mediante el uso de la máscara (Corral Talciani, 1990: 302).

La persona no se identificaba con el moderno concepto de sujeto de derecho, puesto que ésta describía al ser humano en general, de manera que incluso los esclavos podían ser denominados persona servi sin poseer, en cambio, los derechos de la persona libre. En realidad, los derechos solo podían ser ejercidos por personas que tuvieran cierto rango social, al que los romanos denominaron status. La posibilidad de poseer este rango estaba sustentada en tres condiciones: ser libre, poseer la ciudadanía romana y ser cabeza de familia (paterfamilias). Por tal razón, el concepto jurídico de per- 
sona fue asociado finalmente con el estatus social caracterizado por estas tres cualidades (Corral Talciani, 1990: 302-303).

Gracias a que los valores romanos más importantes, como la libertad, la autonomía y la responsabilidad, se asociaron a la noción jurídica de persona, se pudo desarrollar una noción moral de la misma. De esta manera, la persona pasó a constituirse como la verdadera naturaleza del individuo, de suerte que la función social de la máscara dio paso a la interiorización del concepto de perso$n a$, preparando, así, el posterior desarrollo cristiano. En efecto, al concepto jurídico-moral de persona, el cristianismo le otorgó un carácter sagrado al punto que lo concibió como una entidad metafísica (Pewzner, 1999: 271).

Debido al gran debate teológico acerca de la Trinidad, la evolución del concepto de persona adquirió una relevancia histórica sin precedentes. La persona no podía identificarse ya ni con la existencia biológica del individuo ni con el estatus social, porque la doble naturaleza de Jesús hacía de ella una entidad de carácter espiritual. De esta manera, Jesús, el hijo biológico de María, se hizo persona solo a través de su unión hipostática con la segunda persona de la Trinidad, el hijo del Padre espiritual (Bueno, 1996: 122).

Así, el cristianismo judío originario, gracias a la obra de $\mathrm{Pa}-$ blo, especialmente conceptualizada en su Epistola a los Romanos, se adaptó a la vida del imperio y reemplazó la figura del Mesías resucitado por la de Cristo como prototipo del ser humano universal. Cada individuo, identificado con el cuerpo y la sangre de Cristo a través de la eucaristía, pasó a formar parte del cuerpo místico de Jesús, identificado con la Iglesia, de la cual el propio Cristo era la cabeza (Bueno, 1996: 124).

En lugar de una revolución mesiánica, el cristianismo paulino creó una nueva concepción de la persona según la cual cualquier individuo era elevado a esta condición sin necesidad del estatus romano. El individuo humano recibe así la plenitud de sus dere- 
chos como miembro de la Iglesia, es decir, del cuerpo de Cristo, de la Ciudad de Dios agustiniana. Por medio de Cristo, el individuo humano será, entonces, persona humana y, al mismo tiempo, persona divina. La unión hipostática de Cristo se reproduce así en todos los cristianos (Bueno, 1996: 127-128).

El monje romano Boecio trasladó a la filosofía la experiencia religiosa cristiana y reinterpretó la noción de persona en los siguientes términos: "sustancia individual de naturaleza racional". ${ }^{1}$ Sin embargo, en la definición de Boecio, si bien la persona se predica solo de las sustancias individuales, aquello que la define como tal no es su individualidad, sino su sustancialidad. En este sentido, siguiendo a Aristóteles, la sustancia está determinada por la forma, no por la materia del compuesto, de manera que la individualidad permanece como un accidente de la sustancia. Por tal razón, aunque la persona sea concebida como una sustancia individual, no puede aún ser considerada un individuo en sentido pleno (Culleton, 2010: 62).

Un segundo momento en la evolución del concepto filosófico cristiano de persona lo constituye el abad medieval Ricardo de San Víctor. En su obra acerca de la Trinidad, intenta alejarse del concepto aristotélico de sustancia y propone, a partir del personalismo agustiniano, una doctrina relacional de la noción de persona. En tal sentido, la define como: "el existente por sí mismo con cierto modo singular de existencia racional". ${ }^{2}$ Contra Boecio, Ricardo de San Víctor sostiene que el concepto de sustancia no puede dar cuenta de la identidad personal, porque describe una realidad indeterminada, mientras que la persona siempre es una realidad particular y concreta (Culleton, 2010: 63-64).

\footnotetext{
1 "persona est naturaerationalis individua substantia".

2 "persona sit existens per se solum juxta singularem quemdam rationalis existentiae modum”.
} 
Por tal razón, introduce la noción de existencia para reemplazar a la de sustancia. Así, mientras que la sustancia es compartida por varios individuos que participan de ella, la existencia posee una propiedad que solo le pertenece al individuo singular, razón por la cual es incomunicable a los otros individuos. Se trata, por tanto, de una propiedad personal original que hace que alguien sea una persona precisamente. A diferencia de Boecio, quien sostiene que la persona es la propia naturaleza racional, Ricardo de San Víctor sugiere que la persona es el alguien en el cual existe la naturaleza racional. La persona es entonces la portadora concreta de una naturaleza, no el accidente de una sustancia (Culleton, 2010: 65-66).

Finalmente, Duns Scoto llevó a cabo una profundización de la definición, decisiva no solo para la metafísica, sino especialmente para la jurisprudencia. Para el beato escocés, la persona es "la incomunicabilidad que posee existencia en una naturaleza individual". ${ }^{3}$ En este sentido, a diferencia de Ricardo de San Víctor, la persona, precisamente por ser alguien, no podría identificarse sin más con la individualidad concreta, puesto que ésta, a pesar de ser individual, sigue siendo un algo, no un alguien. Por tal razón, solo en cuanto alguien, la persona posee la individualidad como una cualidad suya, $\mathrm{y}$, al mismo tiempo, al identificarse con la propia incomunicabilidad, la persona es un alguien incomunicable en cuanto tal (Culleton, 2010: 67-68).

Esta nueva concepción le permitió a Scoto, y posteriormente a Ockham, desarrollar los rudimentos del llamado "Derecho subjetivo”. Así, a diferencia del planteamiento tomista según el cual las facultades humanas, entre ellas la voluntad, están primeramente en potencia y luego se actualizan en el curso de la realización de la finalidad específica de cada una de éstas, el planteamiento escotista considera que las facultades ya están en plena actividad antes

3 "persona est incommunicabilis habens existentiam in natura intellectuali". 
de realizar su finalidad específica. Por esta razón, cada hombre es, en cuanto ser singular, una unidad acabada, inconmensurable e incomunicable. El hombre es, dice Scoto, la última soledad del ser (Carpintero, 2003: 64-65).

De esta manera, el Derecho es entendido entonces como dominium, es decir, como poder y señorío que impone la ley, y, análogamente, el hombre, gracias a su libre arbitrio, es concebido como señor de sí mismo y de la realidad que le rodea. Así, toda ley es un acto de voluntad, por lo tanto, siempre obliga, tanto en el caso de la ley natural que proviene de Dios, como en el caso de la ley positiva que proviene del hombre (Carpintero, 2003: 67).

Con esta concepción, nos hallamos ad portas de la concepción de persona, en cuanto sujeto de Derecho, desarrollada durante el absolutismo moderno de la mano de Hugo Grocio y Thomas Hobbes. Grocio sostiene que el Derecho es "una cualidad moral de la persona, en virtud de la cual puede hacer o tener algo lícitamente". 4 Tal cualidad moral es entendida como una facultad, es decir, como un poder, una propiedad y una capacidad para exigir lo merecido. El poder que se ejerce sobre uno mismo es la libertad y el que se ejerce sobre otro, la patria potestad. Con estos elementos, Grocio amplía al ámbito jurídico la noción de poder desarrollada por los nominalistas medievales. Sin embargo, su noción de persona no posee el mismo desarrollo (Zarka, 1999: 34).

Con Thomas Hobbes, la definición que Grocio da del Derecho toma una forma apropiada para una nueva noción de persona. En efecto, para Hobbes, el Derecho, en cuanto cualidad moral, no es más que libertad, es decir, poder sobre uno mismo. ${ }^{5}$ De esta manera, Hobbes diferencia entre Derecho y ley; el Derecho es la

\footnotetext{
4 "qualistas moralis personae competens ad aliquid juste habendum velagendum".

${ }^{5}$ Potestas sui.
} 
libertad de hacer o no hacer, mientras que la ley obliga a una de las dos cosas. Ahora bien, el poder de nuestra libertad, o de nuestro Derecho, tiene como finalidad la preservación de la propia vida de cada hombre. En tal sentido, la noción de persona de Hobbes todavía queda anclada a una comprensión biológica o física del individuo (Zarka, 1999: 36-37).

Posteriormente, la noción de persona fue desarrollada por el jurista alemán Samuel Pufendorf, para quien, a diferencia de Hobbes, el Derecho, precisamente por ser una cualidad moral inherente al ser humano, no podía concebirse solo como la mera libertad para preservar la propia vida. En tal sentido, el Derecho consiste en una relación moral, no física, entre la facultad de hacer y la consiguiente obligación. Así, para Pufendorf, el Derecho queda subordinado a la ley, de manera que la persona se transforma en una institución de la ley (Zarka, 1999: 38-39).

Finalmente, Kant elaboró el concepto más acabado de persona desde el punto de vista jurídico. En efecto, para el célebre filosofo de Könisberg, la persona se concibe como individuo con autonomía ética, es decir, como aquel sujeto que sigue únicamente la ley que él mismo se ha dado a través del imperativo categórico. De esta manera, el individuo absolutamente autónomo se convirtió en el núcleo del nuevo Derecho Natural. Por tal razón, el Derecho se transformó, a su vez, en una expansión de la libertad del sujeto en el mundo externo, de manera que todo el ordenamiento jurídico terminó transformándose en un despliegue de los derechos subjetivos del individuo (Carpintero Benítez, 1989: 226-227).

\section{El problema de la soberanía}

Como se sabe, durante la Edad Media, no existió una unidad política semejante al Estado moderno, puesto que las funciones de la sociedad política medieval eran bastante limitadas, razón por 
la cual tampoco era posible hablar de soberanía. En efecto, su finalidad principal era el ejercicio de la fuerza hacia el exterior y el mantenimiento de la paz y la administración del Derecho en el interior. La intención de desarrollar la economía o la de satisfacer el bienestar de los súbditos no estaba incorporada en la vida política como un fin primordial. En tal sentido, el poder político no estaba centralizado ni poseía una influencia determinante en la vida de los súbditos, puesto que las lealtades feudales entre los diversos grupos sociales lo impedían (Naef, 1973: 8-9).

Desde Carlomagno, el orden político medieval se construyó a partir de una adaptación de las instituciones romanas aún existentes al modelo propuesto por los Padres de la Iglesia. En este orden teológico-político, el emperador ocupaba la cúspide de la jerarquía, la cual estaba constituida de jurisdicciones organizadas verticalmente. El poder supremo del emperador se ejercía como jurisdicción plena, iuridisctio plenissima, no sujeta a restricciones; sin embargo, tal poder, aunque constituía la culminación del ordenamiento jurídico-político, no tenía la facultad de crear a partir de sí mismo el orden, puesto que formaba parte de él. En este sentido, no era un poder absoluto, sino más bien un poder cuya función era mantener unido el ordenamiento jurídico-político existente desde el interior del mismo (Costa, 2007: 48).

Hacia finales del siglo XI, el Papa Gregorio VII reinterpretó la famosa "doctrina de las dos espadas" que el Papa Gelasio I había formulado en el año 494. Esta nueva versión, expresada en la doctrina de la plenitudo potestatis, subordinaba una de las espadas, la del emperador, a la del Papa, de manera que éste no solo tenía la auctoritas para representar a la cristiandad universal, sino también la potestas para gobernarla. De esta manera, el orden jerárquico imperial fue sometido a un orden paralelo similar en cuya cúspide se encontraba el pontífice romano. Sin embargo, la nueva doctrina desarrollaba un nuevo punto de vista respecto a esta jerarquía, 
pues introducía un poder exterior a la jerarquía de las jurisdicciones establecidas. Así, el nuevo poder papal gobernaba la unidad del ordenamiento jurídico-político, pero desde fuera de él (Costa, 2007: 51-52).

Con la introducción del poder papal en la organización política medieval, se produjo lo que algunos historiadores han llamado "revolución papal”, pues se trató de la aparición, por vez primera, de una forma de unidad política que anunciaba el advenimiento del Estado moderno. A partir de este momento, la Iglesia concentró el poder en la figura del Papa y sentó las bases para la constitución del futuro absolutismo y del Estado de Derecho, separándose del orden inmanente sobre el que gobernaba, cosa que no ocurría en el caso del emperador, cuya función siempre había formado parte del ordenamiento jurídico histórico (Berman, 1986).

A diferencia de la sociedad política medieval, el Estado moderno busca el bienestar de sus súbditos, así como el desarrollo de la riqueza y la cultura a lo largo de un territorio determinado. Por tal razón, el Estado se apropió paulatinamente de los espacios que la unidad política medieval había dejado en manos de la nobleza y el clero; asimismo, entró en combate contra las dos grandes instituciones supraestatales que le disputaban la soberanía territorial: el imperio y el papado. Hacia fines de la Edad Media, el poder estatal tomó la forma de una monarquía circunscrita a un territorio determinado (Naef, 1973: 10-11).

Durante la modernidad europea, la noción de soberanía tuvo tres momentos importantes con el absolutismo, el constitucionalismo monárquico y el republicanismo, de Hobbes, Locke y Rousseau respectivamente. La soberanía papal fue primeramente transferida al monarca absoluto, de este pasó al Estado, aunque dividida según la teoría de la separación de los poderes, y, finalmente, se identificó con la voluntad general o popular de manera unitaria (Freund, 1968: 142). 
La definición clásica de la soberanía fue estipulada originariamente por Bodino. Como se sabe, el gran jurista francés desarrolló esta doctrina con la finalidad de oponerse tanto a Maquiavelo, partidario del poder del príncipe, como al monarcómaco Althusio, partidario del poder popular. Para Bodino, ambas posturas ignoraban la dimensión jurídica del poder, razón por la cual consideraba que ambas doctrinas constituían expresiones de dos tipos diversos de tiranía. En este sentido, el gran logro de la Edad Media en materia jurídica había sido someter a todos, incluido el monarca, al Derecho (Carpintero, 1999: 116).

Bodino concibió la soberanía como un poder absoluto enraizado en la figura del monarca, único representante de la voluntad divina, a partir del cual se derivaba la organización total del cuerpo político. En su famosa definición "la soberanía es el poder absoluto y perpetuo de una república”, 6 Bodino no solo describía la naturaleza de la soberanía en función a la perpetuidad del poder de la sociedad política, sino a la ausencia de límites del mismo. En tal sentido, la soberanía es poder perpetuo, porque su ejercicio es permanente; y es absoluta, porque no está limitada por ninguna otra forma de poder (Bodin, 1985: 49).

Según Bodino, el ejercicio de la soberanía se materializa en siete atributos que permiten al príncipe ejercerla efectivamente: dar y derogar leyes, declarar la guerra y hacer la paz, conocer las sentencias de los magistrados, instituir y destituir a los oficiales de alto rango, gravar y eximir tributos, elevar y disminuir el valor de la moneda, y hacer jurar fidelidad a los súbditos. De todos estos atributos, Bodino señala que el principal de ellos es el de dar y derogar leyes (Bodin, 1985: 75).

Las leyes permiten ejercer concretamente la soberanía, porque constituyen el instrumento mediante el cual el príncipe puede

6 "maiestas est summa in cives ac subditos leguibusque soluta potestas". 
actuar adecuadamente según las circunstancias. Al mismo tiempo, confieren legitimidad, pues validan el poder jurídicamente. De esto se deduce que la soberanía no es propiamente poder, sino ejercicio legítimo de éste a través del príncipe. Por tal razón, solo hay soberanía cuando el poder se ejerce: 1) en una circunstancia específica; 2) de manera personal, aunque no subjetiva; y 3) con legitimidad (Bodin, 1985: 58).

A partir de la definición de Bodino, Schmitt hizo un giro decisivo en el estudio de la soberanía. Desde su punto de vista, lo importante de ésta no es el poder en sí mismo, sino su efectividad sobre las circunstancias, de manera que un poder que no sea efectivo no implica realmente soberanía y carece, al mismo tiempo, de legitimidad. Sin embargo, esta efectividad solo se hace patente a través de un dispositivo que no está determinado en Bodino, y que Schmitt identifica con el concepto de decisión.

Así, en el primer capítulo de su Teología Política (1922), Schmitt enuncia una frase ahora famosa: "soberano es quien decide sobre el estado de excepción” (Schmitt, 2009: 13). ${ }^{7}$ Con esta sentencia, el jurista alemán realiza una inversión del planteamiento original, pues, a diferencia de Bodino, Schmitt destaca las condiciones en las que se ejerce la soberanía, no le interesan ni su naturaleza ni su titular. Así, cuando Bodino habla de la capacidad del príncipe para cambiar las leyes según las circunstancias, se introduce, como factores determinantes de la soberanía, la acción del titular y los eventos sobre los que actúa. Por esta razón, la definición que enuncia Schmitt no define directamente a la soberanía, sino al soberano, es decir, a quien ejerce concretamente la soberanía. Precisamente, esta acción solo es posible mediante el despliegue de la voluntad del soberano a través de lo que Schmitt identifica con un acto personal de decisión (Schmitt, 2009: 14-15).

7 “Souverän ist, wer über den Ausnahmezustand entscheidet” (Schmitt, 1923: 5). 
Al mismo tiempo, el cambio de las leyes según las circunstancias no solo implica la decisión del soberano como causa eficiente de este cambio, sino las leyes que deben ser cambiadas. La decisión del soberano cambia el orden jurídico si las circunstancias se lo exigen, razón por la cual, en ese momento, el orden jurídico no tiene existencia concreta más que a partir de la decisión del soberano. El soberano efectúa entonces un acto jurídico mediante el cual el mismo orden jurídico se suspende para ser salvaguardado (Schmitt, 2009: 17-18).

En tercer lugar, la interpretación de Schmitt introduce un elemento de necesidad. Si, en efecto, como sostiene Bodino, las circunstancias determinan la decisión del soberano, entonces se trata de circunstancias que exigen una acción inmediata, pues ponen en peligro la existencia misma del orden jurídico. A pesar de que este tipo de eventualidad no esté tipificado en el texto de Bodino, Schmitt le da un nombre propio, le llama: estado de excepción (Schmitt, 2009: 18-19).

En este sentido, Schmitt interpreta las circunstancias, que obligan al príncipe a transformar el sistema de leyes, como situaciones excepcionales. Por tal razón, concuerda con Bodino en que solo en ese caso se ejerce realmente la soberanía. La decisión soberana no tiene sentido más que a partir de las circunstancias excepcionales que le corresponde afrontar. El orden jurídico surge o se suspende cuando la decisión actúa frente a estas circunstancias, pues el acto constitutivo de la decisión es verdaderamente un acto de fundación, ya que solo la decisión funda, a partir del estado de excepción, tanto la norma como el orden jurídico (Schmitt, 1996: 30-31).

Según Schmitt, con la soberanía, accedemos a la dimensión constitutiva de toda organización política moderna. En ella, la unidad política ya no representa al poder, sino que ella misma se hace cargo de si al suspender el ordenamiento jurídico y asumir el rol jurídico que le corresponde mediante la decisión, de suerte que la 
idea del Derecho se positiviza, y la existencia de la unidad política se preserva. En este sentido, la soberanía no es otra cosa que poder constituyente, mientras que el orden jurídico es poder constituido. La soberanía, como él mismo Schmitt dice, es "la unión del poder supremo fáctico y jurídico" (Schmitt, 2009: 22).

\section{Carl Schmitt: de la persona a la existencia}

En este contexto, debemos preguntarnos, ¿qué lugar tiene el concepto de persona en una doctrina de la soberanía como la de Schmitt que parece negar toda realidad al individuo?

En una de sus primeras obras, titulada El valor del Estado y el significado del individuo (1917), Carl Schmitt sostenía que no existe verdadera oposición entre el Estado y el individuo o entre el Derecho y el individuo, como estamos acostumbrados a pensar, ya que, incluso en los términos más individualistas que podamos utilizar para plantearnos la realidad de los seres humanos, como ocurre en el liberalismo anglosajón, el individuo nunca se confunde con el hombre concreto, porque constituye una realidad ideal que se superpone a él. Así, desde el punto de vista del Derecho, el individuo no es más que una ficción jurídica, es decir, un sujeto de Derecho (Schmitt, 2015: 71).

Por tal razón, para Schmitt, el problema de la autonomía del individuo frente al Estado carece de sentido, puesto que el individuo, en cuanto ficción jurídica, ya forma parte del orden jurídico, debido a que el propio Estado no es más que el encargado de actualizar la idea del Derecho. De esta manera, la autonomía es una cualidad que no pertenece ni al individuo ni al Estado, sino al Derecho, cuya finalidad es legitimar el poder inherente al cuerpo social. En cambio, cuando el individuo recupera su autonomía y, por tal razón, deja de formar parte del Derecho, retorna a lo que Hobbes ha llamado "estado de naturaleza" (Schmitt, 2015: 70). 
De esta manera, tanto cuando hablamos del orden jurídico como cuando nos referimos al sujeto de Derecho, la suspensión del orden jurídico, en el caso de una situación excepcional, trae consigo la desaparición de ambos. Bajo tales condiciones, el soberano aparece para restituir, a través de un acto de decisión, tanto el ordenamiento jurídico-político cuanto el sujeto de Derecho. Sin embargo, el acto del soberano se sitúa a nivel de la existencia concreta del orden jurídico-político, no a nivel de su contenido normativo. A tal existencia concreta, Schmitt la denomina "lo político", pues constituye la sustancia desde la que surge el Estado como modo de estar de un pueblo (Schmitt, 1991: 49).

En efecto, contra lo que sostienen los publicistas modernos, el Estado no es una realidad originaria, sino que deriva de una instancia previa a la que Schmitt identificó con el término de poder constituyente. En él, se reúnen, de manera excepcional, las capacidades del legislador y del dictador, es decir, el Derecho no constituido y el poder constituido respectivamente. Precisamente, con el poder constituyente, el legislador se transforma en un legislador dictatorial y el dictador, en un dictador constitucional, de manera que surge lo que Schmitt ha denominado dictadura soberana (Schmitt, 2003a: 172).

Este poder originario nace como resultado del conflicto al que puede llegar el enfrentamiento entre grupos sociales, es decir, "al grado máximo de intensidad de una unión o separación”, que se pone al descubierto, como criterio de lo político, en la distinción amigo-enemigo (Schmitt, 1991: 57). En este sentido, el poder constituyente es "la voluntad política cuya fuerza o autoridad es capaz de adoptar la concreta decisión de conjunto sobre modo y forma de la propia existencia politica, determinando así la existencia política como un todo" (Schmitt, 2003b: 93-94).

En este sentido, lo político debe entenderse como la dimensión existencial de la sociedad que, a partir del antagonismo concreto 
decisivo, hace posible la aparición del Estado, esto es, de la unidad política correspondiente a la modernidad europea y a sus diferentes concretizaciones históricas como han sido la monarquía, la república o la dictadura. De esta manera, lo político constituye el antagonismo decisivo que agrupa a los hombres en amigos y enemigos y que, en consecuencia, hace posible la aparición de la unidad política. Tal unidad política es soberana, precisamente porque puede decidir en el caso excepcional, esto es, en el caso decisivo, puesto que lo que permite decidir es únicamente el conflicto (Schmitt, 1991: 68-69).

La doctrina de la soberanía de Schmitt, concebida como el resultado de la conjunción del estado de excepción y de la decisión del soberano, tiene su origen en un precedente filosófico poco estudiado. Se trata de la obra del pensador danés Søren Kierkegaard, quien concibió, por primera vez en la historia de la filosofía occidental, la noción de excepción en su famoso libro La repetición. Schmitt, al final del primer capítulo de su Teología politica, introduce un fragmento de esta obra según el cual la excepción explica lo general, y no a la inversa, de suerte que toda norma solo tiene sentido efectivo a partir del caso excepcional (Kierkegaard, 2009a: 210-211).

Además de la noción de excepción, Kierkegaard, en otra obra titulada Temor y temblor, introdujo los conceptos de decisión y suspensión de la ética. Según el pensador danés, cuando el ser humano se enfrenta a una situación inconmensurable para su razón, solo le queda apelar a su voluntad, es decir, a su decisión; sin embargo, para poder ejercerla efectivamente debe suspender la ética, es decir, debe suspender el cumplimiento del ordenamiento moral instaurado por la sociedad. Para explicar tal experiencia, Kierkegaard recurre al ejemplo bíblico de Abraham, quien se ve compelido por Dios a sacrificar a su hijo Isaac y, de esta manera, 
a trasgredir el orden normativo de la sociedad de su época (Kierkegaard, 2009b: 143).

Como es evidente, Schmitt ha extrapolado estos tres conceptos del pensamiento kierkegaardiano a su propia concepción de la soberanía. De esta manera, a diferencia de los publicistas de su época, ha concebido al Estado, ya no como una persona juridica, abstracta e impersonal, sino, más bien, como una existencia concreta que alcanza su plenitud gracias al antagonismo político. En ella, el carácter personal de la soberanía tiene lugar gracias a la decisión del soberano frente al estado de excepción que trae como consecuencia la suspensión del ordenamiento jurídico vigente.

Del mismo modo, la noción de persona, en cuanto sujeto de Derecho, sufre una profunda transformación gracias a este punto de vista. En efecto, en cuanto ficción jurídica, el sujeto de Derecho es solo un centro de imputación de la norma abstracta. Sin embargo, como sostiene Kierkegaard, cuando el individuo es sometido por circunstancias que superan su racionalidad, necesita recuperarse a sí mismo precisamente frente a las normas, de manera que debe decidir por el fundamento de su existencia o simplemente no hacerlo y perderse en la generalidad de la abstracción legal.

Vemos entonces que tanto el Estado como el individuo forman parte de dos esferas ontológicas diferentes: una ideal y otra real. Por un lado, ambos participan de la personalidad ideal que el orden jurídico otorga a todos sus miembros; por otro lado, ambos son existencias reales que forman parte de la dinámica política. Con justicia, podemos decir que, en ambos casos, se produce un salto en la constitución de la unidad personal, sea que la concibamos desde un punto de vista social o individual.

De esta manera, mediante la decisión, así como el Estado deja de ser una persona jurídica para transformarse en una existencia politica, el sujeto de derecho deja de ser una persona natural para transformarse en un existente politico. En ambos casos, aquello que 
determina la existencia es la capacidad para decidir, como Abraham ante Dios, frente a la situación excepcional que la vida y los acontecimientos obligan a afrontar en medio del conflicto, porque la decisión es el único instrumento que poseen los seres humanos para actualizar tanto la unidad de su personalidad como la de sus instituciones.

Ahora bien, la unidad de la personalidad, surgida del ejercicio de la decisión, es la instancia por la que la esfera ideal de la personalidad se articula con la esfera real de la existencia. En este sentido, la unidad de la personalidad ya no pertenece ni a la esfera ideal del orden jurídico ni a la esfera real de la política. Se trata, más bien, de una nueva esfera a la que Kierkegaard ha llamado espiritu. En efecto, el espíritu es aquello que hace posible la unidad de lo finito y lo infinito:

El hombre es espíritu. Mas, ¿qué es el espíritu? El espíritu es el yo. Pero ¿qué es el yo? El yo es una relación que se relaciona consigo misma, o, dicho de otra manera: es lo que en la relación hace que ésta se relacione consigo misma. El yo no es la relación, sino el hecho de que la relación se relacione consigo misma. El hombre es una síntesis de infinitud y finitud, de lo temporal y lo eterno, de la libertad y la necesidad, en una palabra: es una síntesis. Y una síntesis es la relación entre dos términos (Kierkegaard, 2008: 33).

El espiritu solo acontece ahí donde la decisión hace posible que la existencia se oponga a la persona, es decir, ahí donde la esfera real destruye a la esfera ideal. De esta manera, surge la unidad de la personalidad, esto es, el espiritu, al que Kierkegaard identifica con el estadio religioso: "lo paradójico-religioso rompe con la inmanencia y hace que existir sea la contradicción absoluta; no dentro de la inmanencia, sino en oposición a la inmanencia" (Kierkegaard, 2010: 554). 
Por su parte, Schmitt identifica esta dimensión con aquello que ha denominado principio de la representación. Como se sabe, "En la representación, por el contrario, adquiere apariencia concreta una alta especie del ser" (Schmitt, 2003b: 209). Esta alta especie del ser no es otra cosa que un tipo de existencia espiritual que distingue al gobierno estatal tanto de un funcionario subordinado como de un opresor violento. De esta manera, la representación constituye la unidad de la personalidad del Estado de un pueblo (Schmitt, 2003b: 213).

La representación no es un fenómeno de carácter normativo, no es un procedimiento, sino algo existencial. Representar es hacer perceptible y actualizar un ser imperceptible mediante un ser de presencia pública. Esto no es posible con cualquier especie del ser, sino que supone una particular especie del ser. Una cosa muerta, desvalorizada o desprovista de valor, una cosa inferior no puede ser representada. Le falta la superior especie del ser, que es susceptible de una elevación al ser público, de una existencia. Palabras tales como grandeza, alteza, majestad, gloria, dignidad y honor, tratan de acercar con esa singularidad del ser elevado y susceptible de representación. [...] La idea de la representación se basa en que un pueblo existente como unidad política tiene una alta y elevada, intensiva, especie del ser, frente a la realidad natural de cualquier grupo humano con comunidad de vida (Schmitt, 2003b: 209)

Debido a que la unidad espiritual se alcanza únicamente gracias al ejercicio de la decisión frente al estado de excepción, podemos afirmar que la representación es el resultado de la desaparición del orden jurídico frente a la voluntad política. Esta conjunción negativa produce la ruptura de la inmanencia jurídico-política del Estado, de suerte que, a través de ella, se actualiza el mysterium tremendum (Otto, 2005: 22) constitutivo de todo poder soberano. 
Nacionalidad y autoridad forman, juntas, un único objeto: el Estado que, con ello, cobra carácter religioso. El Estado no solo posee a sus propios dioses, sino que él mismo es dios. Carl Schmitt ha demostrado, de manera convincente, que la ideología del Estado, la razón de Estado, no es sino teología secularizada (Van der Leuw, 1964: 261).

El Estado es, entonces, aquel Dios mortal del que hablaba Hobbes; sin embargo, a diferencia de éste, el Dios mortal de Schmitt no está clausurado en la inmanencia, sino que, herido de muerte, se abre a la trascendencia. Gracias al estado de excepción, es posible acceder, a partir de la decisión, a la espiritualidad de la unidad de la personalidad. De esta manera, la persona ha dejado lugar a la existencia y ésta ha dado paso al espíritu: el Estado ya no es una persona, sino un espíritu.

\section{Bibliografía}

Berman, Harold, 1986, La formación de la tradición jurídica de Occidente, Fondo de Cultura Económica, México.

Bodin, Jean, 1985, Los seis libros de la república, Editorial Tecnos, Madrid.

Bueno, Gustavo, 1996, El sentido de la vida, Pentalfa, Oviedo.

Carpintero Benítez, Francisco, 1989, La cabeza de Jano, Servicio de Publicaciones de la Universidad de Cádiz, Cádiz.

Carpintero, Francisco, et. al., 2003, "El desarrollo de la facultad individual en la Escolástica", en El Derecho subjetivo en su historia, Servicio de Publicaciones de la Universidad de Cádiz, Cádiz. 
Corral Talciani, Hernán, 1990, "El concepto jurídico de persona. Una propuesta de reconstrucción unitaria”, Revista chilena de Derecho, vol. 17, pp. 310-321.

Costa, Pietro, 2007, "La soberanía en la cultura político-jurídica medieval: imágenes y teorías”, Res publica, vol. 17, pp. 33-58.

Culleton, Alfredo, 2010, "Tres aportes al concepto de persona. Boecio (sustancia), Ricardo de San Víctor (existencia) y Escoto (incomunicabilidad)", Revista Española de Filosofía Medieval, vol. 17, pp. 59-71.

Freund, Julien, 1968, La esencia de lo político, Editora Nacional, Madrid.

Kierkegaard, Søren, 2008, La enfermedad mortal, Editorial Trotta, Madrid.

,2009a, La repetición, Alianza Editorial, Madrid.

, 2009b, Temor y temblor, Alianza Editorial, Madrid.

, 2010, Post Scriptum no cientifico y definitivo a las Migajas filosóficas, Editorial Sígueme, Salamanca.

Naef, Werner, 1973, La idea del Estado en la Edad Moderna, Editorial Aguilar, Madrid.

Otto, Rudolf, 2005, Lo santo. Lo racional y lo irracional en la idea de Dios, Alianza Editorial, Madrid.

Pewzner, Evelyne, 1999, El hombre culpable. La locura y la falta en Occidente, Universidad de Guadalajara/Fondo de Cultura Económica, Guadalajara, México.

Schmitt, Carl, 1923, "Soziologie des Souveränitätsbegriffes und politische Theologie“, en Palyi, M. (Hg.), Hauptprobleme der Soziologie. Erinnerungsgabe für Max Weber, Bd. 2, München/ Leipzig, pp. 3-35.

, 1991, El concepto de lo político. Texto de 1932, un prólogo y tres corolarios, Alianza Editorial, Madrid. 
1996, Sobre los tres modos de pensar la ciencia jurídica, Editorial Tecnos, Madrid.

, 2003a, La Dictadura. Desde los comienzos del pensamiento moderno de la soberania hasta la lucha de clases proletaria, Alianza Editorial, Madrid.

, 2003b, Teoría de la Constitución, Alianza Editorial, Madrid.

,2009, Teología politica. Cuatro capitulos sobre la doctrina de la soberanía, Editorial Trotta, Madrid.

,2015, El valor del Estado y el significado del individuo, Centro de Estudios Constitucionales, Madrid.

Van der Leuw, Gerardus, 1964, Fenomenología de la religión, Fondo de Cultura Económica, México.

Zarka, Yves-Charles, 1999, "La invención del sujeto de derecho", Isegoría, núm. 20, pp. 31-49. 